\title{
COLABORACION PROFESIONAL
}

\section{Cómo puede organizarse un Archivo municipal}

Entre las distintas actividades a que se hallan sometidas modernamente las Oficinas municipales, va adquiriendo una merecida importancia la organización y funcionamiento del Archivo.

Se suceden las disposiciones abligando a la formación de índices y catálogos, encomendando estos menesteres a los Secretarios de Ayuntamiento, que no cuentan con personal especializado, y, en fin, la obligación de las Corporaciones de tener montado en forma el Archivo es un hecho.

Por ello hemos creído que de alguna utilidad podría ser la experiencia obtenida en el Archivo municipal de Guecho desde 1928, en que lo organizamos, siguiendo las enseñanzas del ilustre Archivero y Cronista de Bilbao don Teófilo Guiard (q. e. p. d.), a quien debemos la iniciación en estas tareas y a quien en realidad corresponde todo el mérito del sistema, pues que a nosotros no nos cabe más que el título de discípulos y seguidores.

La organización de un Archivo inunicipal debe abarcar la ordenación de todos los papeles, documentos y libros pertenecientes al Ayuntamiento desde la fecha más remota hasta los actuales tiempos, y por ello el plan que se adopte debe contener, además de los conceptos de derivaciones impuestas por las Ordenanzas y Leyes municipales vigentes en sus tiempos, los pertinentes conceptos particulares y de individualización de asuntos referidos a Instituciones, Prácticas y Obligaciones, actualmente en desuso o no existentes, de mero valor histórico, así como los conceptos de adaptación le las obligaciones del Ayuntamiento a las vigentes disposiciones.

El Plan de organización ha de comprender un numero de Cuadros sinópticos adecuado a las características históricas y administrativas de cada Municipio; será variable, pues, su número.

Cacla uno de estos Cuadros generales abarca, numerados corre- 
lativarnente, los conceptos que se estiman necesarios para completar de modo real los fondos existentes, y no hay inconveniente alguno en ir adicionando conceptos con su número correspondiente cuando lo exijan las circunstancias o hayan de acomodarse nuevas disposiciones que se dicten, que no hubieran sido reflejadas debidamente en su lugar pertinente.

Las operaciones inherentes a la ordenación del Archivo, una vez fijados los Cuadros sinópticos o Agrupaciones que auteceden, se proseguirán de la manera siguiente:

Advertido como más práctico el empleo de carpetas cerradas, en forma libro, se adopta el tipo más conveniente en orden a dimensiones (nosotros escogimos la de 35 centímetros de alto por 28 centímetros de largo y 10 centímetros de ancho) para la guarda de los papeles.

Estas carpetas deben llevar en la parte superior del lomo la indicación: aAyuntamiento de...», sobremontando el escudo municipal, y en el tercio inferior de dicho lomo la señalación "Sección...., y debajo, aLegajo núm.... .

La uniformidad de carpetas establece de hecho una subordinación de los expedientes a las mismas, y en el caso de que el volumen del expediente no pueda ser incluído en una sola carpeta, se formarán con él piezas separadas con numeración correlativa, distribuyéndolas en las sucesivas carpetas que exigieren.

Se custodiarán los expedientes así enlegajados en armarios, que pueden ser de madera o metálicos: siendo los más corrientes los de seis a siete baldas, cada uno de los cuales quedará individualizado con la indicación aSección primera, segunda, etc.n, hasta completarlas.

Las carpetas ocuparán los estantes a que fueron destinados en sucesión regular, llevando en el espacio inmediato a la rotulación aSección...v el número respectivo de la misma y una numeración progresiva del 1 a su final en el espacio que sigue a la indicación aI egajo.... .

Los Libros de Actas, de Contabilidad, expedientes de quintas $\mathrm{y}$ otros cualesquiera que por exigencias de encuadernación o cosido ofrecieran formatos no sujetos a medida, se colocarán en la baldería de los armarios, regulándose con la necesidad impuesta por la diferencia de tamaños; pero dichos dccumentos, al igual que los encarpetados, serán colocados en su aSección y con la misma rigurosa indicación de número de Sección y número progresivo de carpetá que los anteriormente dichos.

Todos lcs expedientes que ingresen en el Archivo serán sella- 
dos en la parte superior izquierda de la cubierta con el sello propio del Ayuntamiento y uno particular que diga: Archivo $\mathrm{Mu}$ nicipal. E En su línea o en la parte media del tercio superior de la misma cubierta se estampará la indicación: aSección... Legajo... Numero...p con los espacios necesarios para la posición de cifras adecuadas. Esta signatura corresponde a la coordinación del expediente con la ficha o cédula de su referencia $e$ indice respectivo, y se colocará simultaneando con la redacción de dicha ficha o cédula.

Las fichas o cédulas que han de formar posteriormente los libros Indices y Catálagos pueden ser de cualquiera de los sistemas conocido, pero el más conveniente resulta el de fichas libres, unidas por debajo por una varilla que $\epsilon$ vite el que puedan traspapelarse.

Estas fichas deben comprender el total asunto, fondo del expediente, advertido que el extracto que ha de hacerse del mismo seal claro y conciso, y en los casos en que dicho asunto, fondo del expediente, comprenda derivaciones importantes por incidencias acaecidas durante la tramitación del mismo, y en él incluídas, se harán tantas fichas separadas y pertinentes como sean necesarias. Del mismo modo se simultanearán las referencias cuanto sea conveniente para mayor claridad de investigación y facilidad de busca de expediente.

Las fichas o cédulas pueden ir confeccionadas del siguiente modo: En la parte superior izquierda llevarán en numeros romanos el de la Agrupación general o Cuadro que corresponda, seguido del que al concepto adecuado dentro de dicha Agrupación sea pertinente, en numeración arábiga ; en la parte central, la signatura con la indicación de la Sección, Legajo y Número que corresponde, como ya indicamos a la coordinación del expediente con la ficha de su referencia e índice respectivo; en la parte superior derecha, el año, debiendo colocarse el de la terminación del expediente. Si en la tramitación de éste ha transcurrido más de un año, conviene hacer tantas fichas como años haya durado. El resumen del expediente, conciso y claro, se colocará debajo de las indicaciones preceĺentes en el cuerpo de la ficha.

Una vez fínalizada la redacción de fichas, se procederá a la escritura de las mismas en los libros que forman el Catálogo e Indices del Archivo, libros del tamaño proporcionado que se adopte, subdividiéndose dichos Indices conforme a los Cuadros sinópticos o Agrupaciones establecidas.

Esta transcripción se realizará cuĩdadamente, concertándola a las 
Agrupaciones generales y conceptos generales y particulares de dicho Cuadro orgánico y guardando el oportuno rigor de referencia y signaturas.

El orden de transcripción en los Indices será rigurosamente cronológico en cada uno de los Cuadros en que se incluyen.

Enlegajados, signados y coordinados los documentos del Archivo, para la suficiente custodia de ellos y exigencias del servicio puede cumplirse un cuerpo de disposiciones análogas al que sigue:

1. Corresponde al Secretario de la Corporación la inspección directa e inmediata de dicha dependencia, teniendo la iniciativa y dïrección de todos los trabajos que se ejecuten en la misma.

2. Los empleados del Archivo no podrán suministrar a oficinas ni particulares cuantos datos y noticias tengan alguna relación con los papeles que en él se guardan, sin que para ello hayan precedido acuerdo del Ayuntamiento, disposición del Alcalde y orden del Secretario.

3. El Archivo municipal no está autorizado para recibir papel alguno $\sin$ que medie disposición escrita del Alcalde o Secretario que así lo ordene.

4. El Archivo no admitirá papeles a granel o en desorden, debiendo incluirse inventario detallado, en el cual se hagan constar con toda la claridad posible cada uno de sus extractos.

$5^{\circ}$ Como consecuencia de lo que antecede, el Archivo exigirá la presentación de dos ejemplares de cada inventario de papeles de que haya de hacerse cargo, uno en el cual conste el a.Recibín del Archivero y sirva de resguardo al que entrega y otro que conserve como garantía de seguridad en la oficina.

La identidad de ambos ejemplares será comprobala por el Archivo y la persona o personas encargadas de la entrega.

6. Cuando se trate de un expediente $y$, por lo tanto, se considere ińtilil la formación de inventario, bastará la orden escrita del Secretario, sirviendo ésta de resguardo a la Oficina, que tendrá, a su vez, obligación de acusar recibo para seguridad de Secretaría.

7. Todas las Dependencias municipales harán la entrega, de papeles por medio de la Secretaría, de quịen finicamente debe recibirlos el Archivo.

8. El Archivo se halla obligado a facilitar con la mayor brevedad posible a las Oficinas y a cualquier persona o entidad autorizada para ello cuantos antecedentes se le pidan y se custodien entre sus papeles. 
9. Para la entrega de papeles por parte del Archivo tendrán lugar las siguientes formalidades:

a) Extensión de un recibo encabezado con la oruen firmada del Secretario.

b) El recibí del que se hace cargo del documento.

10. El documento o expediente que se pida no podrá salir del Archivo sin los requisitos antes indicados.

11. Los pedidos que se dirijan al Archivo deberán formularse por escrito, debiendo hacerse constar el extracto del expediente $y$, a ser posible, la fecha del mismo.

12. En el mes de diciembre, el Archivo pasará anualmente al Secretario una relación detallada de todos los documentos que, mechiante recibo, hayan salido del Archivo y no devueltos para que se tomen las medidas oportunas. 